\title{
Early Return to Physical Activity After a Concussion: A Critically Appraised Topic
}

\author{
Jessica St Aubin, MAT, ATC, ${ }^{1}$ Jennifer Volberding, PhD, LAT, ATC, ${ }^{2}$ and Jack Duffy, MAT, LAT, ATC \\ ${ }^{1}$ Sideline Orthopedics and Sport; ${ }^{2}$ Oklahoma State University Center for Health Sciences; ${ }^{3}$ Oral Roberts University
}

Clinical Question: How does early return to physical activity impact return-to-play recovery time in patients 5-30 years old after an acute concussion as compared to the current best practice of resting? Clinical Bottom Line: Based on the information gathered, there is moderate evidence to support the incorporation of light to moderate physical activity within 7 days after a concussion in order to decrease recovery time and symptoms.

Keywords: mTBI, early exercise, return to play

\section{Clinical Scenario}

Concussions are a growing epidemic and these injuries can have extremely serious and debilitating consequences to patients. Athletic trainers need to determine the safest and most effective method of treatment for patients with a concussion. Current best practices state that, "After a patient is diagnosed with a concussion, Phase 1 , which is no activity, is followed until he or she no longer reports concussionrelated symptoms, has a normal clinical examination, and performs at or above preinjury levels of functioning on all objective concussion assessments. Then the patient will begin the Return to Play (RTP) protocol. Phase 2 includes light exercise, $70 \%$ age-predicted maximal heart rate. Phase 3 is sport-specific activities without the threat of contact from others. Phase 4 includes noncontact training involving others and resistance training. Phase 5 is Unrestricted training. And finally Phase 6 is full Return to Play."3(p247)

When a patient has a concussion or concussive injury, athletic trainers should follow current best practices. The National Athletic Trainers' Association (NATA) position statement for concussions currently follows a protocol of rest followed by activity, as outlined above. This protocol is viewed as best practice currently, however, recent research has shown that this can severely

St Aubin is with Sideline Orthopedics and Sport, Arlington, TX, USA. Volberding is with the Oklahoma State University Center for Health Sciences, Tulsa, OK, USA. Duffy is with Oral Roberts University, Tulsa, OK, USA. St Aubin (staubin@yahoo.com) is corresponding author. impact a patient's recovery time and return to play and have a lifelong impact if not properly treated and rehabilitated. ${ }^{1,2,4,5}$ With the current best practice of no activity until the patient is completely symptom free, many patients end up with a delay in recovery and return to play. Current research is now suggesting that incorporating exercise earlier on in the healing process can aid in faster overall recovery. ${ }^{1,2,4,5}$ This early activity will allow the athletic trainer more opportunities to improve return to activity and reduce long-term impacts. This could also contribute to more honest and accurate symptom scoring as the patient is able to recover and return to activity faster.

\section{Focused Clinical Question}

How does early return to physical activity impact returnto-play recovery time in patients 5-30 years old after an acute concussion as compared to the current best practice of resting?

\section{Search Strategy}

- Population: patients ages 5-30 who have sustained a concussion

- Intervention: Early (within 7 days) return to physical activity

- Comparison: control group or rest group

- Outcome: Decreased recovery/return-to-play (RTP) time

\section{Sources}

- PubMed

- Google Scholar

- Medline

- EBSCO Host

- Cochrane

\section{Search Terms}

- Acute concussion

- Early exercise 
- Physical activity

- Acute concussion exercise

- Acute concussion early physical activity

\section{Inclusion Criteria}

- Humans only

- English only

- Past 10 years (2008-2018)

- Patients began exercise within 7 days of acute concussion

- Patients between the ages of 5-30 years old

\section{Exclusion Criteria}

- Studies looking at postconcussive syndrome

- Animal studies
- Recovery of longer than 35 days

- Studies not including physical activity

\section{Evidence Quality Assessment}

To determine the quality of evidence for the included articles, the Oxford Evidence-Based Medicine Scale was utilized. All articles for this Critically Appraised Topic are at the level of $2 \mathrm{~b}$. This means that there is a moderate to high quality of evidence and applicability for clinical professionals.

\section{Results of Search}

Based on the searches conducted, thousands of articles were identified. After reviewing titles, 20 articles were considered. After reviewing the abstracts, only eight articles remained that matched all inclusion and exclusion criteria. Of those eight articles, three

Table 1 Characteristics of Included Studies

\begin{tabular}{|c|c|c|c|c|}
\hline \multirow[b]{2}{*}{ Characteristics } & \multicolumn{4}{|c|}{ Authors } \\
\hline & Buckley et al. ${ }^{1}$ & Grool et al. ${ }^{4}$ & Lawrence et al. ${ }^{2}$ & Majerske et al. ${ }^{5}$ \\
\hline Study title & $\begin{array}{l}\text { Acute cognitive and physi- } \\
\text { cal rest may not improve } \\
\text { concussion recovery time }\end{array}$ & $\begin{array}{l}\text { Association between early } \\
\text { participation in physical activ- } \\
\text { ity following acute concussion } \\
\text { and persistent post concussive } \\
\text { symptoms in children and } \\
\text { adolescents }\end{array}$ & $\begin{array}{l}\text { Earlier time to aerobic exercise } \\
\text { is associated with faster } \\
\text { recovery following acute sport } \\
\text { concussion }\end{array}$ & $\begin{array}{l}\text { Concussion in sports: Post } \\
\text { concussive activity levels, } \\
\text { symptoms, and neurocognitive } \\
\text { performance }\end{array}$ \\
\hline Participants & $\begin{array}{l}50 \text { college athletes with } \\
\text { concussions diagnosed } \\
\text { before and after a policy } \\
\text { change }^{3}\end{array}$ & $\begin{array}{l}3,063 \text { participants aged } 5 \text { to } \\
17.99 \text { years old with acute head } \\
\text { injuries within the last } 48 \mathrm{hr} \\
\text { seen in the emergency } \\
\text { department }\end{array}$ & $\begin{array}{l}253 \text { participants with acute } \\
\text { concussions; } 148 \text { males } \\
(58.5 \%) \text { and } 105(41.5 \%) \\
\text { females }\end{array}$ & $\begin{array}{l}95 \text { student-athletes; } 80 \text { males, } \\
15 \text { females; two groups ages } \\
13-15 \text { or age } 16-18^{2}\end{array}$ \\
\hline Intervention & $\begin{array}{l}\text { No-rest group patients were } \\
\text { not provided any postinjury } \\
\text { accommodations; rest group } \\
\text { patients were withheld from } \\
\text { activities and classes }\end{array}$ & $\begin{array}{l}\text { Participants were divided into } \\
\text { the exercise within } 7 \text { days group } \\
\text { versus the no activity group; } \\
\text { evaluated for the presence of } \\
\text { participation and postconcus- } \\
\text { sion symptoms (PPCS) }\end{array}$ & $\begin{array}{l}\text { The amount of aerobic activity } \\
\text { was monitored. } \\
\text { The time at which the prescribed } \\
\text { exercise was initiated, as } \\
\text { opposed to prescribed, was used } \\
\text { to define the time to exposure. }{ }^{4}\end{array}$ & $\begin{array}{l}\text { Evaluated activity intensity, } \\
\text { symptoms and neurocognitive } \\
\text { outcome up to } 33 \text { days after } \\
\text { concussion in } 5 \text { groups based } \\
\text { on postinjury activity intensity }\end{array}$ \\
\hline Outcome & $\begin{array}{l}\text { The no-rest group were } \\
\text { symptom free sooner than } \\
\text { the rest group; no other dif- } \\
\text { ferences were noted. }\end{array}$ & $\begin{array}{l}\text { Moderate activity levels re- } \\
\text { ported lower symptom levels } \\
\text { and better neurocognitive } \\
\text { performance. }\end{array}$ & $\begin{array}{l}\text { The median time to aerobic } \\
\text { exercise was } 8.0 \text { days postin- } \\
\text { jury. The median time to full } \\
\text { return to sport was } 28.0 \text { days. }\end{array}$ & $\begin{array}{l}\text { Sex appears to be the only } \\
\text { independent variable contrib- } \\
\text { uting to the likelihood of } \\
\text { prolonged clinical follow-up. } \\
\text { When females returned to play } \\
\text { in the same sport, they had } \\
\text { above average performance but } \\
\text { males did not. }\end{array}$ \\
\hline Results & $\begin{array}{l}\text { Cognitive and physical rest } \\
\text { following a concussion was } \\
\text { not effective for reducing } \\
\text { postconcussion recovery } \\
\text { time. }\end{array}$ & $\begin{array}{l}\text { Participation in physical activity } \\
\text { within } 7 \text { days of acute injury } \\
\text { compared with no physical } \\
\text { activity was associated with } \\
\text { lower risk of PPCS at } 28 \text { days. }{ }^{1}\end{array}$ & $\begin{array}{l}\text { Starting aerobic exercise post- } \\
\text { concussion more quickly was } \\
\text { associated with faster full } \\
\text { return to sport and school/ } \\
\text { work. Symptoms and recovery } \\
\text { delay increases following } \\
\text { complete or prolonged rest } \\
\text { after concussion. }{ }^{4}\end{array}$ & $\begin{array}{l}\text { Younger athletes were more } \\
\text { prone to prolonged symptoms } \\
\text { than older athletes after } \\
\text { concussion. }\end{array}$ \\
\hline $\begin{array}{l}\text { Evidence quality } \\
\text { score (Oxford } \\
\text { Evidence-Based } \\
\text { Medicine Scale) }\end{array}$ & $2 b$ & $2 b$ & $2 b$ & $2 b$ \\
\hline $\begin{array}{l}\text { Support for the } \\
\text { answer }\end{array}$ & Yes & Yes & Yes & Yes \\
\hline
\end{tabular}


were summaries of one article already included and one was unavailable. Table 1 summarizes the included studies.

\section{Results of Evidence Quality Assessment}

Many strengths exist with this study. First, there is a multitude of information on the topic of concussion. Second, the information gathered in these studies is very important and relevant. Any patient in any activity can sustain a concussion, therefore, having information on the best return-to-play guidelines is extremely important. While there were strengths to this research, there were also weaknesses. One weakness was the fact that it was difficult to find consistent research with similar parameters and measurements. Additionally, each article had different and sometimes unclear definitions of terms such as moderate exercise versus light exercise.

\section{Clinical Bottom Line}

Based on the information gathered, there is moderate evidence to support the incorporation of light to moderate physical activity within 7 days after a concussion in order to decrease recovery time and symptoms.

\section{Implications for Practice, Education, and Future Research}

Based on data gathered through the reviewed articles, rest with absolutely no activity was shown to prolong recovery among all studies. ${ }^{1,2,4,5}$ The overall consensus from these studies was that starting light to moderate physical activity which one article defined as "jogging, running, swimming, cycling, or utilization of stationary aerobic equipment"2(p3) within 7 days (the earlier the better) helped to decrease the amount of time it took to return to play, as well as the amount of time it took to decrease symptoms. It was also recommended that patients not participate in activities with high re-injury potential until the patient no longer displays symptoms. According to this information, the current best practices that are being observed by most clinicians are no longer the best practice and should be re-evaluated. Implementing light to moderate physical activity into a concussion return-to-play protocol can help to improve their recovery process. ${ }^{1,2,4,5}$

Some limitations of these articles include lack of definitions of terms. By not having a consistent standard of what light to moderate physical activity is defined as, different medical professionals can interpret the amount of exercise to perform through each stage differently. This also makes it more difficult to compare activities and develop consistent return-to-play protocols.
Findings from Majerske et al. ${ }^{5}$ suggest that age and gender may have a profound impact on return to play and return to learn. This calls for further research into these characteristics and their influence on developing exercise prescriptions in concussion recovery. These findings can impact how much exercise should be prescribed at each age for each gender and may call for further research in order to better understand how physical activity may differ in these situations. If age and gender do play as significant of a role as suggested, this may further change what is considered to be best for the patient and could change the progression for return to play at each age for different genders. These findings could also impact the new sport-specific rules that are meant to help reduce the number of concussions in younger populations. When it comes to concussions and concussion management, the knowledge and information is always evolving. It is important to incorporate this information into everyday clinical practice as it could potentially have a substantial impact on patient care.

\section{CAT Kill Date: May 2022}

CATs have limited life and should be revisited approximately 2 years after publication (see https://doi.org/10.1123/ijatt.20180093).

\section{References}

1. Buckley TA, Munkasy BA, Clouse BP. Acute cognitive and physical rest may not improve concussion recovery time. J Head Trauma Rehabil. 2016;31(4):233-241. PubMed ID: 26394292 doi:10.1097/ HTR.0000000000000165

2. Lawrence DW, Richards D, Comper P, Hutchison MG. Earlier time to aerobic exercise is associated with faster recovery following acute sport concussion. PLoS One. 2018;13(4):e0196062. PubMed ID: 29668716 doi:10.1371/journal.pone.0196062

3. Broglio S, Cantu R, Gioia G, et al. National Athletic Trainers' Association Position Statement: Management of sport concussion. J Athl Train. 2014;49(2):245-265. PubMed ID: 24601910 doi:10. 4085/1062-6050-49.1.07

4. Grool AM, Aglipay M, Momoli F, et al. Association between early participation in physical activity following acute concussion and persistent post concussive symptoms in children and adolescents. JAMA. 2016;316(23):2504-2514. PubMed ID: 27997652 doi:10. 1001/jama.2016.17396

5. Majerske CW, Mihalik JP, Ren D, et al. Concussion in sports: post concussive activity levels, symptoms, and neurocognitive performance. J Athl Train. 2008;43(3):265-274. PubMed ID: 18523563 doi:10.4085/1062-6050-43.3.265 